\title{
A simple and inexpensive enteric-coated capsule for delivery of acid-labile macromolecules to the small intestine
}

\author{
Darren S. MILLER ${ }^{1}$, Anne Michelle PARSONS ${ }^{1,2}$, John BRESLAND ${ }^{2}$, Paul HERDE ${ }^{3}$, Duc Minh PHAM ${ }^{1}$, \\ Angel TAN ${ }^{4}$, Hung-yao HSU ${ }^{1}$, Clive A. PRESTIDGE ${ }^{4}$, Tim KUCHEL ${ }^{3}$, \\ Rezaul BEGG ${ }^{5}$, Syed Mahfuzul AZIZ ${ }^{\dagger 1}$, Ross N. BUTLER ${ }^{2}$ \\ ( ${ }^{I}$ Division of Information Technology, Engineering and the Environment, School of Engineering, \\ University of South Australia, Mawson Lakes, SA 5095, Australia) \\ $\left({ }^{2}\right.$ Division of Health Sciences, School of Pharmacy and Medical Science, University of South Australia, Adelaide, SA 5000, Australia) \\ $\left({ }^{3}\right.$ Large Animal Research and Imaging Facility, South Australian Health \& Medical Research Institute (SAHMRI), Gilles Plains, SA 5086, Australia) \\ ( ${ }^{4}$ Ian Wark Research Institute, University of South Australia, Mawson Lakes, SA 5095, Australia) \\ $\left({ }^{5}\right.$ Gait and Balance Research Group, Institute of Sport, Exercise and Active Living (ISEAL), Victoria University, Melbourne, VIC 3032, Australia) \\ †E-mail: mahfuz.aziz@unisa.edu.au \\ Received Oct. 28, 2014; Revision accepted Apr. 7, 2015; Crosschecked June 16, 2015
}

\begin{abstract}
Understanding the ecology of the gastrointestinal tract and the impact of the contents on the host mucosa is emerging as an important area for defining both wellness and susceptibility to disease. Targeted delivery of drugs to treat specific small intestinal disorders such as small bowel bacterial overgrowth and targeting molecules to interrogate or to deliver vaccines to the remote regions of the small intestine has proven difficult. There is an unmet need for methodologies to release probes/drugs to remote regions of the gastrointestinal tract in furthering our understanding of gut health and pathogenesis. In order to address this concern, we need to know how the regional delivery of a surrogate labeled test compound is handled and in turn, if delivered locally as a liquid or powder, the dynamics of its subsequent handling and metabolism. In the studies we report on in this paper, we chose ${ }^{13} \mathrm{C}$ sodium acetate $\left({ }^{13} \mathrm{C}\right.$-acetate), which is a stable isotope probe that once absorbed in the small intestine can be readily measured non-invasively by collection and analysis of ${ }^{13} \mathrm{CO}_{2}$ in the breath. This would provide information of gastric emptying rates and an indication of the site of release and absorptive capacity. In a series of in vitro and in vivo pig experiments, we assessed the enteric-protective properties of a commercially available polymer EUDRAGIT ${ }^{\circledR}$ L100-55 on gelatin capsules and also on DRcaps ${ }^{\circledR}$. Test results demonstrated that DRcaps ${ }^{\circledR}$ coated with EUDRAGIT ${ }^{\circledR}$ L100-55 possessed enhanced enteric-protective properties, particularly in vivo. These studies add to the body of knowledge regarding gastric emptying in pigs and also begin the process of gathering specifications for the design of a simple and cost-effective enteric-coated capsule for delivery of acid-labile macromolecules to the small intestine.
\end{abstract}

Key words: Breath testing, Pig, Endoscopic capsule, Gastric emptying, Biomarker delivery, Gastrointestinal tract doi: 10.1631 jzus.B1400290

Document code: A

CLC number: R965

\section{Introduction}

As the immune system of the gastrointestinal (GI) tract constitutes the first line of defence against mu-

\footnotetext{
Corresponding author

Project supported by the Australian Research Council (ARC) Linkage Project Grant (No. LP0990847)

(D) ORCID: Syed Mahfuzul AZIZ, http://orcid.org/0000-0002-9627-7594

(c) Zhejiang University and Springer-Verlag Berlin Heidelberg 2015
}

cosal pathogens (van Ginkel et al., 2000; Holmgren and Czerkinsky, 2005; Takahashi et al., 2009), the ability to deliver acid-labile compounds such as therapeutic drugs and also vaccine antigens directly to the small intestine offers opportunities for non-invasive treatments and vaccination strategies. Although a significant amount of work has been conducted using microencapsulated molecules, sophisticated and expensive equipment is required for these formulations (Sue 
et al., 1993; Shirley et al., 2001; Bueno da Costa et al., 2002; Mccarron et al., 2008). We therefore have developed a simple and inexpensive enteric-stable capsule with an ability to deliver milligram amount payloads to the small intestine of pigs. Non-invasive functional breath tests have been used previously in animal models (Anderson et al., 2002; Pelton et al., 2004; Butler, 2008; Terry et al., 2012) with more applications/examples in humans (Ishii et al., 2001; Festi et al., 2005; Tooley et al., 2006; de Lacy Costello et al., 2013; Pizzoferrato et al., 2013). In our studies, we chose ${ }^{13} \mathrm{C}$ sodium acetate $\left({ }^{13} \mathrm{C}\right.$-acetate $)$ for a surrogate biomarker of "payload" in the GI tract of pigs as it is relatively inexpensive and its metabolism in the duodenum to ${ }^{13} \mathrm{CO}_{2}$ can be non-invasively measured and quantified from exhaled breath, enabling determination of gastric emptying rates (Braden et al., 1995; 2004; Barbosa et al., 2005).

The use of synthetic polymer-coated capsules, which provide protective properties against the low $\mathrm{pH}$ of the stomach while also being rapidly degraded in neutral $\mathrm{pH}$ as encountered in the small intestine, was pivotal in our investigations. In our studies, we used EUDRAGIT ${ }^{\circledR}$ L100-55 (Evonik Industries, Essen, North Rhine-Westphalia, Germany) and DRcaps ${ }^{\circledR}$ $\left(\right.$ Capsuge $^{\circledR}{ }^{\mathbb{B}}$, Morristown, NJ, USA) capsules as they have been extensively reported and marketed to provide exceptional enteric protection while also being rapidly degraded at $\mathrm{pH} 5.5$ (Khan et al., 1999; Terao et al., 2001; Jelvehgari et al., 2010; Calija et al., 2013).

We therefore have instigated in vitro testing and small-scale pig studies using EUDRAGIT ${ }^{\circledR}$ L100-55 coating of both gelatin capsules and also commercially available DRcaps ${ }^{\circledR}$ to investigate proof of concept for an inexpensive but effective capsule with noninvasive end uses in human gastro-intestinal functional studies and therapeutic drug/vaccine delivery.

\section{Materials and methods}

\subsection{Capsule coating and in vitro studies}

In our current study we first embarked on in vitro experiments to determine the basic properties that would be required to provide enteric stability of the ${ }^{13} \mathrm{C}$-acetate payload. Following consultation with Evonic Industries and the use of in-house technologies, we developed the following capsule coating protocol. Gelatin capsules (size 000) were filled with $250 \mathrm{mg}$ of crystal violet and a stainless steel bar $(6.3 \mathrm{~mm} \times$ $12 \mathrm{~mm}$ ). Loaded capsules were then arranged in a dipping tray and suspended in a pre-prepared EUDRAGIT ${ }^{\circledR}$ L100-55 mixture (EUDRAGIT ${ }^{\circledR}$ L10055, 9.0 g; polyethylene glycol 400, $1.4 \mathrm{~g}$; Tween 80, $0.1 \mathrm{~g}$; acetone, $38 \mathrm{ml}$; isopropyl alcohol, $57 \mathrm{ml}$; and water, $5 \mathrm{ml}$ ) for $15 \mathrm{~s}$, permitting $2 / 3$ of the capsules' surface to be coated and then allowed to dry for $30 \mathrm{~min}$. Capsules were then inverted and re-inserted into the dipping tray and the remaining $1 / 3$ of the capsules' surface was coated. Capsules were subsequently placed on the laboratory bench at ambient temperature and allowed to completely dry for $72 \mathrm{~h}$. Specific residual solvent analysis was not performed; however, all coated capsules were free of acetone odor after $72 \mathrm{~h}$ of drying. In a series of experiments, we then tested the in vitro enteric protective ability of both the DRcaps ${ }^{\circledR}$ and gelatin capsules coated with EUDRAGIT $^{\circledR}$ L100-55 either once, twice, thrice, or four times. Uncoated gelatin capsules or commercially available DRcaps ${ }^{\circledR}$ capsules used for controls were loaded with crystal violet and the stainless steel bar but were not EUDRAGIT ${ }^{\circledR}$ L100-55 coated. As we intended to perform an in vitro release (or dissolution) study using crystal violet dye as the test compound, a paddle system dissolution apparatus was used in accordance with pharmacopoeia standards. In these experiments, a dissolution bath (USP 23 type II Apparatus Vankel VK6010, Varian Inc., Palo Alto, CA, USA) was assembled and pre-warmed to $37^{\circ} \mathrm{C}$. A volume of $400 \mathrm{ml}$ of $0.1 \mathrm{~mol} / \mathrm{L} \mathrm{HCl}(\mathrm{pH} 1.0)$ was placed into $3 \times$ dissolution cups and rotation was set at $100 \mathrm{r} / \mathrm{min}$. Enteric protection/capsule integrity, as measured by visual detection after release of blue color, was assessed at 60,90 , and $120 \mathrm{~min}$. At the 120-min mark, $200 \mathrm{ml}$ of $0.05 \mathrm{~mol} / \mathrm{L}$ phosphate buffer $\left(\mathrm{Na}_{2} \mathrm{HPO}_{4}, \mathrm{pH} 7.5\right)$ was added to the cups, effectively adjusting the $\mathrm{pH}$ to 7.0 , representative of porcine intestinal conditions (Evans et al., 1988) and also in accordance with the $\mathrm{pH}$ range (6.8-8.0) as accepted by the U.S. Food and Drug Administration Guidance for Industry (http://www.fda.gov/downloads/drugs/ guidancecomplianceregulatoryinformation/guidances/ ucm070237.pdf). Integrity was again monitored until the capsule had disintegrated ( $n \geq 3$ for each different capsule coating type). 


\subsection{In vivo pig studies}

In vivo studies were conducted on a total of thirteen female Large White $\times$ Duroc pigs (age 812 weeks) obtained from the Roseworthy Campus, University of Adelaide (Roseworthy, Australia) and subsequently housed at the South Australian Health and Medical Research Institute Animal Facility at Gilles Plains in Adelaide, Australia. The pigs were housed singularly alongside neighboring companions in raised metal cages $(2 \mathrm{~m} \times 2 \mathrm{~m})$ with rubber matting covering the bottom surface of the enclosures. During maintenance periods, food and water were provided ad libitum. Room temperature was maintained at $20{ }^{\circ} \mathrm{C}$ with a 12-h light/12-h dark cycle.

Prior to the procedures, all animals were fasted from food overnight but allowed access to water. In all studies, a baseline breath sample was taken from the pigs $5 \mathrm{~min}$ prior to gavage. Pigs were briefly anaesthetized via an intramuscular injection of $20 \mathrm{mg} / \mathrm{kg}$ of ketamine (100 mg/ml) (CEVA Animal Health, Glenorie NSW, Australia) delivered through an $18 \mathrm{G}$ needle. Once fully anaesthetized, a measured length of $12 \mathrm{~mm}$ inner diameter (ID) polypropylene tubing was then placed through the mouth and directed carefully into the stomach. To assess the liquid gastric emptying time, pigs were gavaged via tubing with $250 \mathrm{mg}$ of ${ }^{13} \mathrm{C}$-acetate dissolved in $100 \mathrm{ml}$ of water via a $30-\mathrm{ml}$ syringe. To elucidate the gastric emptying time and the enteric protective capabilities of the EUDRAGIT ${ }^{\circledR}$ L100-55, pigs were gavaged with a quadruple-coated gelatin capsule containing $250 \mathrm{mg}$ of powdered ${ }^{13} \mathrm{C}$-acetate followed by $100 \mathrm{ml}$ of acidified water ( $\mathrm{pH} 3.5$ ) via a $30-\mathrm{ml}$ syringe. Finally, we aimed to demonstrate both the gastric liquid emptying phase and the enteric protective properties of EUDRAGIT ${ }^{\circledR}$ L100-55 simultaneously in an individual pig. In these studies, $250 \mathrm{mg}$ of powdered ${ }^{13} \mathrm{C}$-acetate was enclosed in a size 0 DRcaps ${ }^{\mathbb{B}}$ which had been placed into a size 00 DRcaps $^{\circledR}$ (double DRcaps $\left.{ }^{\circledR}\right)$. The outer DRcaps ${ }^{\circledR}$ was also further coated with EUDRAGIT ${ }^{\circledR}$ L100-55 four times (quadruple-coated). In these later studies, groups of pigs were gavaged with $250 \mathrm{mg}$ of ${ }^{13} \mathrm{C}$-acetate dissolved in $100 \mathrm{ml}$ of acidified water $(\mathrm{pH} \mathrm{3.5)}$ via a 30-ml syringe, simultaneously with the quadruplecoated, double DRcaps ${ }^{\circledR}$. In all studies, exhaled breath samples were collected from conscious pigs using an adapted mask set up constructed from a cut down lower end of an empty intravenous bag with the outlet tube attached to a 3-way stopcock and 20-ml syringe. This mask was held over the pig's snout while the syringe plunger was withdrawn. By closing the stopcock, the breath sample could be transferred to evacuated tubes for analysis. ${ }^{13} \mathrm{CO}_{2}$ was measured using the SerCon Automated Breath ${ }^{13} \mathrm{C}$ Isotope Ratio Mass Spectrometer (SerCon, Crewe, UK). Breath test results are shown as the change from baseline of the ratio of ${ }^{13} \mathrm{C} /{ }^{12} \mathrm{C}$ detected in the expired $\mathrm{CO}_{2}$ (Symonds et al., 2008). $\mathrm{CO}_{2}$ levels were always checked to ensure consistent sampling.

\section{Results}

\subsection{In vitro studies}

Under the low $\mathrm{pH}$ conditions ( $\mathrm{pH} 1.0$ ), the singly and doubly coated gelatin capsules had completely disintegrated within $30 \mathrm{~min}$. The uncoated control gelatin capsules had completely disintegrated within 5 min (data not shown). Conversely, gelatin capsules triple-coated or quadruple-coated with the EUDRAGIT $^{\circledR}$ L100-55 survived for 60 (Figs. 1a and 1e) and $90 \mathrm{~min}$ (Figs. $1 \mathrm{~b}$ and 1f), respectively, without any visible sign of disintegration. Slight disintegration of triple-coated gelatin capsules was observed at $120 \mathrm{~min}$ (Fig. 1c). However, quadruple-coated gelatin capsules survived $120 \mathrm{~min}$ without evident dye leakage under these conditions (Fig. 1g). Subsequent exposure of the triple- and quadruple-coated $\left(\right.$ EUDRAGIT $^{\circledR}$ ) gelatin capsules to $\mathrm{pH} 7.0$ resulted in total disintegration after $30 \mathrm{~min}$ (Figs. 1d and $1 \mathrm{~h}$ ). In preliminary in vitro experiments, uncoated DRcaps ${ }^{\circledR}$ surprisingly disassembled into two separate pieces within 90 min of exposure to $\mathrm{pH} 1$ with disintegration occurring at the closure seal of the capsule (data not shown) and therefore was not used for initial in vivo studies.

\subsection{In vivo pig studies}

The initial stage to establish the utility of the pig model of gastric emptying was to determine a doseresponse curve with ${ }^{13} \mathrm{C}$-acetate administered in a liquid form. As expected, release of ${ }^{13} \mathrm{CO}_{2}$ in the breath of the pigs was detected within 5 min of gavage and rapidly peaked within 45 min (Figs. 2a and 2b). The height of the individual peaks also demonstrated a dose-response profile of ${ }^{13} \mathrm{CO}_{2}$ release in the breath 

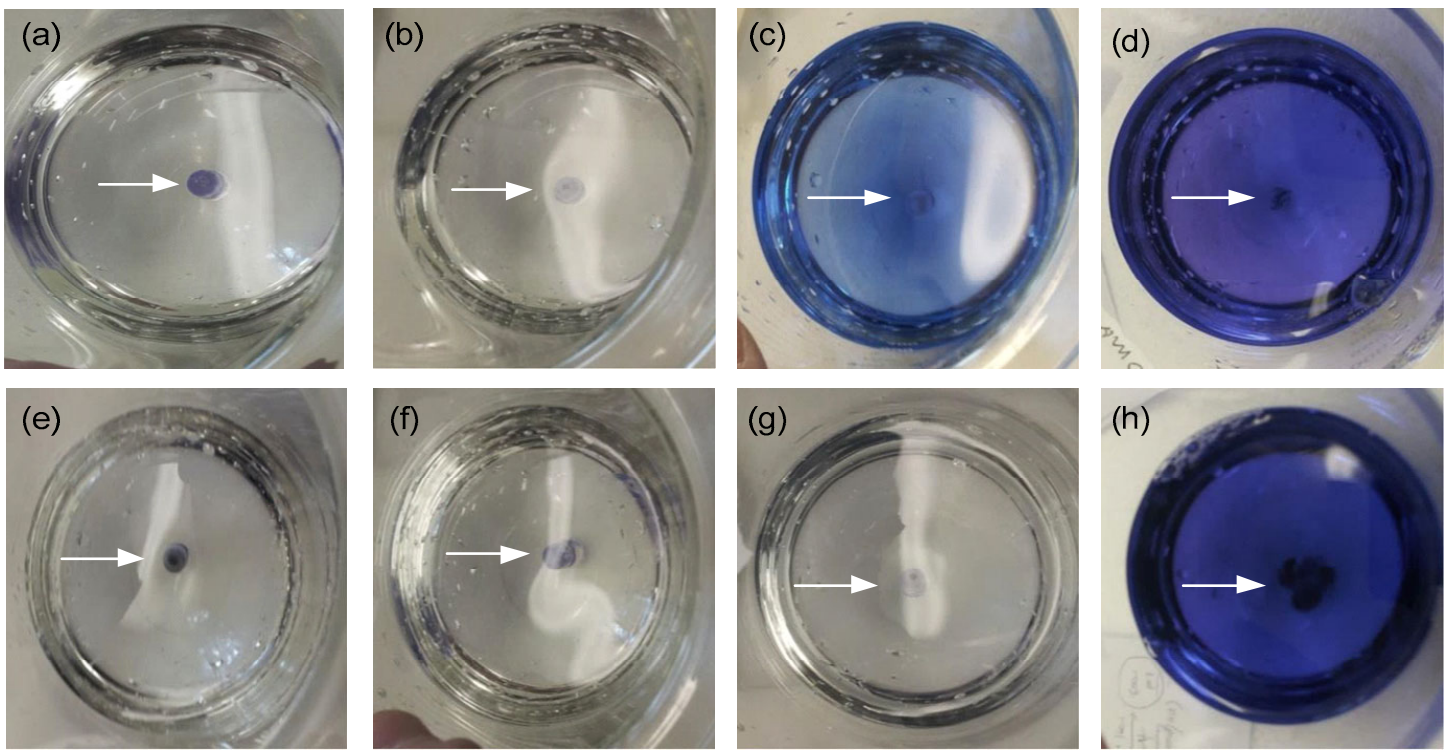

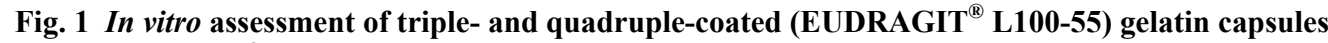

Triple-coated (EUDRAGIT ${ }^{\circledR}$ L100-55) capsule integrity following incubation for 60 (a), 90 (b), and 120 min (c) at pH 1.0 and then $30 \mathrm{~min}$ at $\mathrm{pH} 7.0$ (d). Quadruple-coated (EUDRAGIT ${ }^{\mathbb{B}}$ L100-55) capsule integrity following incubation for 60 (e), 90 (f), and $120 \mathrm{~min}(\mathrm{~g})$ at $\mathrm{pH} 1.0$ and then $30 \mathrm{~min}$ at $\mathrm{pH} 7.0$ (h). All incubations were conducted at $37{ }^{\circ} \mathrm{C}$ with $100 \mathrm{r} / \mathrm{min}$ rotation. All pictures are plan views of the dissolution cups. Blue areas indicate dye content release
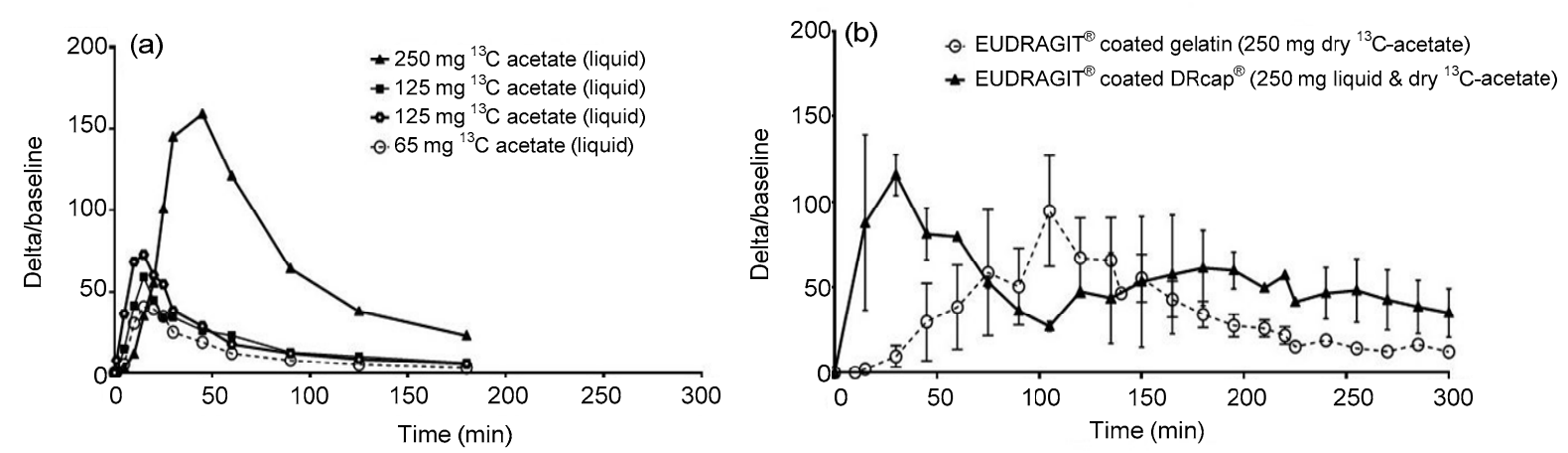

Fig. $2{ }^{13} \mathrm{CO}_{2}$ release in the breath of pigs following dosing with either liquid or enteric-coated capsules containing powdered ${ }^{13} \mathrm{C}$-acetate

(a) In the first set of small-scale pilot studies, pigs ( $n=1$ per dose) were gavaged with 250,125 , or $65 \mathrm{mg}$ of ${ }^{13} \mathrm{C}_{\text {-acetate dis- }}$ solved in $100 \mathrm{ml}$ water. (b) In the second set of pilot studies, pigs were gavaged with $250 \mathrm{mg}$ of powdered ${ }^{13} \mathrm{C}$-acetate in a gelatin capsule quadruple-coated with EUDRAGIT ${ }^{\mathbb{B}} \mathrm{L} 100-55(n=4)$ or with $250 \mathrm{mg}$ of ${ }^{13} \mathrm{C}$-acetate dissolved in $100 \mathrm{ml}$ acidified water simultaneously with $250 \mathrm{mg}$ of powdered ${ }^{13} \mathrm{C}$-acetate enclosed in a double DRcaps ${ }^{\circledR}$ quadruple-coated with EUDRAGIT $^{\circledR}$ L100-55 $(n=2)$. Breath samples were collected throughout the duration of the study and assessed for the presence of ${ }^{13} \mathrm{CO}_{2}$ and expressed as delta/baseline. Data are represented as mean and standard error of the mean

(Fig. 2a: $250 \mathrm{mg}$, peak 159; $125 \mathrm{mg}$, peaks 62 and 73; $65 \mathrm{mg}$, peak 41) confirming the reproducibility of this protocol. We next compared the release of ${ }^{13} \mathrm{CO}_{2}$ in the breath following dosing of pigs with powdered ${ }^{13} \mathrm{C}$-acetate delivered in gelatin capsules quadruplecoated with EUDRAGIT ${ }^{\circledR}$ L100-55. We observed a significant delay in the release of ${ }^{13} \mathrm{CO}_{2}$ with the average ${ }^{13} \mathrm{CO}_{2}$ peak observed at $110 \mathrm{~min}$ after the capsule administration, compared with a peak occurring at around $30 \mathrm{~min}$ after the ${ }^{13} \mathrm{C}$-acetate was administered in the liquid form indicating release of the labelled ${ }^{13} \mathrm{CO}_{2}$ in the small intestine (Fig. 2b). In our final study, we investigated the combined administration of $250 \mathrm{mg}$ of ${ }^{13} \mathrm{C}$-acetate in a liquid form simultaneously with $250 \mathrm{mg}$ of powdered ${ }^{13} \mathrm{C}$-acetate in a double DRcaps ${ }^{\circledR}$ quadruple-coated with EUDRAGIT ${ }^{\circledR}$ 
L100-55. In these studies, where pigs were dosed with both liquid ${ }^{13} \mathrm{C}$-acetate simultaneously with EUDRAGIT ${ }^{\circledR}$ L100-55 coated DRcaps ${ }^{\circledR}$ we observed a biphasic profile of ${ }^{13} \mathrm{CO}_{2}$ release. The first peak appeared at $30 \mathrm{~min}$ post-dosing representing the liquid gastric emptying phase. This was followed by a significantly delayed and broader peak at $180 \mathrm{~min}$ indicative of duodenal release of the ${ }^{13} \mathrm{C}$-acetate. These results demonstrated the enhanced entericprotective properties of the EUDRAGIT ${ }^{\circledR}$ L100-55 coated DRcaps ${ }^{\circledR}$ compared with EUDRAGIT ${ }^{\circledR}$ L100-55 coated gelatin capsules.

\section{Discussion}

Fundamental to our studies was the development of an in vivo assay to assess gastric emptying. In our initial studies, we observed reproducible doseresponse curves for ${ }^{13} \mathrm{CO}_{2}$ release in the breath of pigs and these results enabled us to effectively assess the enteric-stability of our coated capsules (Fig. 2a). Preliminary in vitro studies clearly demonstrated the utility of EUDRAGIT ${ }^{\circledR}$ L100-55 for enteric-like protection of gelatin capsules. However, this protection was less evident in the gastro-intestinal tract of a pig. We therefore tested the in vivo protective capability of EUDRAGIT ${ }^{\circledR}$ L100-55 coated gelatin capsules and also to further enhance the entericprotective properties of our capsules, EUDRAGIT ${ }^{\mathbb{B}}$ L100-55 coated DRcaps ${ }^{\circledR}$. In these studies, where pigs were dosed with liquid ${ }^{13} \mathrm{C}$-acetate simultaneously with powdered ${ }^{13} \mathrm{C}$-acetate in a double DRcaps ${ }^{\circledR}$ quadruple-coated with EUDRAGIT ${ }^{\circledR}$ L100-55, we observed a biphasic profile of ${ }^{13} \mathrm{CO}_{2}$ release. The first peak was evident at $30 \mathrm{~min}$ post-dosing representing the liquid gastric emptying phase, followed by a significantly delayed and broader peak at $180-220 \mathrm{~min}$, which is indicative of duodenal release of the ${ }^{13} \mathrm{C}$-acetate. These observations indicate a superior gastric-stability of the EUDRAGIT ${ }^{\circledR}$ L100-55 coated DRcaps ${ }^{\circledR}$ over EUDRAGIT ${ }^{\circledR}$ L100-55 coated gelatin capsules. To our knowledge, this data is the first to apply a direct comparison of the enteric-stability of EUDRAGIT ${ }^{\circledR}$ L100-55 coated capsules and DRcaps ${ }^{\circledR}$ in vitro and in vivo in a pig model. Additionally, these results add to the body of knowledge regarding gastric emptying in pigs and the utility of non-invasive breath testing when the probe is delivered directly to the small intestine.

In conclusion, this current study investigated the combined use of enteric-protective coatings, breath tests, and the collection of preliminary specifications for the design of a simple but effective capsule for use in both pigs and humans with the aim of optimizing the construction of novel, non-invasive devices and targeted therapeutics. It showed that breath tests are feasible when the probe $\left({ }^{13} \mathrm{C}\right.$-acetate) $)$ is delivered in situ in the small intestine in powdered form in a capsule suitably coated with enteric-protective coatings. Compared with oral delivery of ${ }^{13} \mathrm{C}$-acetate in liquid form, significant delays in the release of ${ }^{13} \mathrm{CO}_{2}$ were observed when ${ }^{13} \mathrm{C}$-acetate powder was delivered either in gelatin capsule or in DRcaps ${ }^{\circledR}$ both quadruple-coated with EUDRAGIT ${ }^{\circledR}$ L100-55. The breath test signals also showed different patterns when compared with ${ }^{13} \mathrm{C}$-acetate delivered orally in liquid form; however, the aggregate signal was similar. The DRcaps ${ }^{\circledR}$ demonstrated enhanced entericprotective properties compared with the gelatin capsules when both were coated with EUDRAGIT ${ }^{\circledR}$ L100-55. Finally, these studies describe the effectiveness of a simple and inexpensive endoscopic capsule, which is able to deliver powdered compounds to the duodenum of pigs, signifying the potential for use for studies aimed at delivering acidlabile compounds to the lower gastro-intestinal tract. Related studies have also signified the potential for tracking the location of the capsule within the GI tract (Pham and Aziz, 2014).

\section{Acknowledgements}

We wish to thank Evonik Industries for their kind gift of the EUDRAGIT ${ }^{\circledR}$ L100-55 and also Capsugel ${ }^{\circledR}$ for their supply of the DRcaps ${ }^{\circledR}$. We acknowledge Associate Professor Taher OMARI of the Women's and Children's Hospital, Adelaide, Australia for additional supportive funding. We also acknowledge Pfizer Australia, Sydney, NSW, Australia for additional funding.

\section{Compliance with ethics guidelines}

Darren S. MILLER, Anne Michelle PARSONS, John BRESLAND, Paul HERDE, Duc Minh PHAM, Angel TAN, Hung-yao HSU, Clive A. PRESTIDGE, Tim KUCHEL, Rezaul BEGG, Syed Mahfuzul AZIZ, and Ross N. BUTLER declare that they have no conflict of interest. 
All animal studies were approved by the SA Pathology/ Central Health Network Animal Ethics Committee in accordance with the Australian code of practice for the care and use of animals for scientific purposes.

\section{References}

Anderson, D.L., Bartholomeusz, F.D., Kirkwood, I.D., et al., 2002. Liquid gastric emptying in the pig: effect of concentration of inhaled isoflurane. J. Nucl. Med., 43(7): 968-971.

Barbosa, L., Vera, H., Moran, S., et al., 2005. Reproducibility and reliability of the ${ }^{13} \mathrm{C}$-acetate breath test to measure gastric emptying of liquid meal in infants. Nutrition, 21(3):289-294. [doi:10.1016/j.nut.2004.05.027]

Braden, B., Adams, S., Duan, L.P., et al., 1995. The $\left[{ }^{13} \mathrm{C}\right]$ acetate breath test accurately reflects gastric emptying of liquids in both liquid and semisolid test meals. Gastroenterology, 108(4):1048-1055. [doi:10.1016/0016-5085(95)90202-3]

Braden, B., Peterknecht, A., Piepho, T., et al., 2004. Measuring gastric emptying of semisolids in children using the ${ }^{13} \mathrm{C}$-acetate breath test: a validation study. Dig. Liver. Dis., 36(4):260-264. [doi:10.1016/j.dld.2003.12. 011]

Bueno da Costa, M.H., Quintilio, W., Tanizaki, M.M., et al., 2002. Heat shock protein micro-encapsulation as a double tool for the improvement of new generation vaccines. $J$. Liposome Res., 12(1-2):29-35. [doi:10.1081/LPR-120004 773]

Butler, R.N., 2008. Non-invasive tests in animal models and humans: a new paradigm for assessing efficacy of biologics including prebiotics and probiotics. Curr. Pharm. Des., 14(14):1341-1350. [doi:10.2174/1381612 08784480180]

Calija, B., Cekic, N., Savic, S., et al., 2013. pH-sensitive microparticles for oral drug delivery based on alginate/ oligochitosan/Eudragit ${ }^{\mathbb{B}}$ L100-55 "sandwich" polyelectrolyte complex. Colloids Surf. B Biointerfaces, 110:395-402. [doi:10.1016/j.colsurfb.2013.05.016]

de Lacy Costello, B.P., Ledochowski, M., Ratcliffe, N.M., 2013. The importance of methane breath testing: a review J. Breath Res., 7(2):024001. [doi:10.1088/1752-7155/7/2/ 024001]

Evans, D.F., Pye, G., Bramley, R., et al., 1988. Measurement of gastrointestinal $\mathrm{pH}$ profiles in normal ambulant human subjects. Gut, 29:1035-1041. [doi:10.1136/gut.29.8.1035]

Festi, D., Capodicasa, S., Sandri, L., et al., 2005. Measurement of hepatic functional mass by means of ${ }^{13} \mathrm{C}$-methacetin and ${ }^{13} \mathrm{C}$-phenylalanine breath tests in chronic liver disease: comparison with Child-Pugh score and serum bile acid levels. World J. Gastroenterol., 11(1):142-148. [doi:10. 3748/wjg.v11.i1.142]

Holmgren, J., Czerkinsky, C., 2005. Mucosal immunity and vaccines. Nat. Med., 11(Suppl. 4):S45-S53. [doi:10.1038/ $\mathrm{nm} 1213]$

Ishii, T., Furube, M., Hirano, S., et al., 2001. Evaluation of ${ }^{13} \mathrm{C}$-phenylalanine and ${ }^{13} \mathrm{C}$-tyrosine breath tests for the measurement of hepatocyte functional capacity in patients with liver cirrhosis. Chem. Pharm. Bull. (Tokyo), 49(12):1507-1511. [doi:10.1248/cpb.49.1507]

Jelvehgari, M., Zakeri-Milani, P., Siahi-Shadbad, M.R., et al., 2010. Development of $\mathrm{pH}$-sensitive insulin nanoparticles using Eudragit L100-55 and chitosan with different molecular weights. AAPS PharmSciTech, 11(3):12371242. [doi:10.1208/s12249-010-9488-7]

Khan, M.Z., Prebeg, Z., Kurjakovic, N., 1999. A pHdependent colon targeted oral drug delivery system using methacrylic acid copolymers. I. Manipulation of drug release using Eudragit L100-55 and Eudragit S100 combinations. J. Control. Release, 58(2):215-222. [doi:10. 1016/S0168-3659(98)00151-5]

Mccarron, P.A., Donnelly, R.F., Al-Kassas, R., 2008. Comparison of a novel spray congealing procedure with emulsion-based methods for the micro-encapsulation of water-soluble drugs in low melting point triglycerides. $J$. Microencapsul., 25(6):365-378. [doi:10.1080/02652040 802000656]

Pelton, N.S., Tivey, D.R., Howarth, G.S., et al., 2004. A novel breath test for the non-invasive assessment of small intestinal mucosal injury following methotrexate administration in the rat. Scand. J. Gastroenterol., 39(10): 1015-1016. [doi:10.1080/00365520410003416]

Pham, D.M., Aziz, S.M., 2014. A real-time localization system for an endoscopic capsule using magnetic sensors. Sensors, 14(11):20910-20929. [doi:10.3390/s141120910]

Pizzoferrato, M., del Zompo, F., Mangiola, F., et al., 2013. Specific ${ }^{13} \mathrm{C}$ functional pathways as diagnostic targets in gastroenterology breath-tests: tricks for a correct interpretation. Eur. Rev. Med. Pharmacol. Sci., 17(Suppl. 2): 45-50.

Shirley, I.M., Scher, H.B., Perrin, R.M., et al., 2001. Delivery of biological performance via micro-encapsulation formulation chemistry. Pest Manag. Sci., 57(2):129-132. [doi:10.1002/1526-4998(200102)57:2<129::AID-PS265> 3.0.CO;2-1]

Sue, M.S., Liu, K.M., Yu, H.S., 1993. The gastro-intestinal absorption of griseofulvin can be enhanced by encapsulation into liposomes. Kaohsiung J. Med. Sci., 9(1):1-8.

Symonds, E.L., Tran, C.D., Butler, R.N., et al., 2008. Gastric emptying is altered with the presence of gastritis. Dig. Dis. Sci., 53(3):636-641. [doi:10.1007/s10620-0079928-8]

Takahashi, I., Nochi, T., Yuki, Y., et al., 2009. New horizon of mucosal immunity and vaccines. Curr. Opin. Immunol., 21(3):352-358. [doi:10.1016/j.coi.2009.04.002]

Terao, T., Matsuda, K., Shouji, H., 2001. Improvement in site-specific intestinal absorption of furosemide by Eudragit L100-55. J. Pharm. Pharmacol., 53(4):433-440. [doi:10.1211/0022357011775721]

Terry, R., van Wettere, W.H., Whittaker, A.L., et al., 2012. Using the noninvasive ${ }^{13} \mathrm{C}$-sucrose breath test to measure intestinal sucrase activity in swine. Comp. Med., 62(6): 504-507. 
Tooley, K.L., Saxon, B.R., Webster, J., et al., 2006. A novel non-invasive biomarker for assessment of small intestinal mucositis in children with cancer undergoing chemotherapy. Cancer Biol. Ther., 5(10):1275-1281. [doi:10.4161/cbt.5. 10.3303]

van Ginkel, F.W., Nguyen, H.H., Mcghee, J.R., 2000. Vaccines for mucosal immunity to combat emerging infectious diseases. Emerg. Infect. Dis., 6(2):123-132. [doi:10.3201/eid0602.000204]

\section{中文概要} 题 : 一种用于递送酸度敏感大分子到小肠的简易且廉
价的肠溶胶囊
目 的: 通过开展胃肠道远端释放药物的研究, 以增加对 肠道健康和发病机制的理解。

创新点: 本研究选择了 ${ }^{13} \mathrm{C}$ 醋酸钠作为同位素探针, 通过 收集和分析呼吸中的 ${ }^{13} \mathrm{CO}_{2}$ 来非侵入测量其在小 肠吸收的情况。这将提供胃排空率的信息及释放 和吸收位点的指标。

方 法: 在一系列体外和体内的猪实验中, 评估了 EUDRAGIT $^{\circledR}$ L100-55 和 DRcaps ${ }^{\circledR}$ 两种胶囊的肠 溶保护特性。

结 论: 包覆有 EUDRAGIT ${ }^{\circledR}$ L100-55 的 DRcaps $^{\circledR}$ 具有增强 的肠溶保护性能, 特别是在体内。本研究增加了 对猪胃排空的了解, 同时也开始设计用于递送酸 度敏感大分子到小肠的简易且廉价的肠溶胶囊。

关键词: 呼吸测试; 猪; 内功能性胶囊; 胃排空 